\title{
EL DINERO Y LA LIBERTAD MODERNA
}

\author{
Andrés Bilbao
}

Universidad Complutense de Madrid

\begin{abstract}
RESUMEN
La noción de libertad moderna guarda estrecha relación con la libertad individual. La argumentación de Simmel se asienta en el principio de que no son los seres humanos, sino el dinero, lo que establece las relaciones sociales. La libertad individual implica el cierre del individuo sobre sí mismo y, por medio del dinero, la capacidad para calcular y prever la realización de su deseo.
\end{abstract}

Uno de los ejes argumentales de la obra de Simmel consiste en señalar que la modernidad es sinónimo de exclusión de las formas antropomórficas de la voluntad como principio constitutivo del orden social. Ni la voluntad del príncipe ni la del ciudadano configuran las relaciones entre los individuos. La sociedad es resultado de la tensión entre la vida y las formas. Aquélla proporcionará los contenidos que adquirirán autonomía en las formas, que se desenvolverán hasta independizarse respecto de la vida. Esto señala el momento de la plena constitución de la organización social. Las formas son configuraciones cristalizadas que se destacan e independizan frente al ser viviente, en el que tienen su origen.

Simmel señala que cada época ha implicado un particular punto de partida desde el que se despliegan las formas que constituyen la organización social.

\section{Reis}


En el mundo griego fue el Ser; en la Edad Media, Dios; en el Renacimiento, la Naturaleza; tras Kant, el Yo'. La autonomía del yo, el obrar independiente de la causalidad natural era, para Kant, el origen del obrar moral. Esta autonomía del yo era el punto de partida de la acción moral desde la que se construía la sociabilidad $^{2}$. Autónomo es aquel individuo que libremente determina su acción, lo que equivale a decir que la determina al margen de su naturaleza ${ }^{3}$.

Este enfoque que parte el yo, compartido también por Nietzsche, supone que el mundo exterior sólo deviene racional a partir de la acción del sujeto. Lo que separa a Nietzsche respecto de Kant es el distinto contenido del deber moral ${ }^{4}$, pero su forma existe lo mismo que en Kant, y en realidad más inmediatamente y con más fuerza, puesto que el imperativo de Kant no pretende más que formular un factum de la razón humana, mientras que los valores de Nietzsche tienen en sí mismos un carácter imperativo. Para Kant, el teórico objetivo con su imperativo, no quiere más que formular un factum de la razón, sígase o no de hecho, siempre existirá como ideal fuera del tiempo; en cambio, Nietzsche, el moralista práctico, quiere formular un nuevo ideal, demanda una nueva exigencia ${ }^{5}$. La moral práctica alude al modo en el que se configura el orden como proyección de la voluntad. Simmel señala que la voluntad es lo que determina que el mundo objetivo tenga carácter de fin. La voluntad es una forma psicológica que coexiste con otras formas psicológicas, tales como el ser, el deber y la esperanza. Mediante las fuerzas psicológicas el sujeto recoge el contenido ideal del mundo y lo traduce a algo con significación para el sujeto ${ }^{6}$. La naturaleza es causalidad mecánica que aparece ante el sujeto como un conjunto sin regla ni orden. El conocimiento y la voluntad establecen la unidad en la multiplicidad, actuando sobre la base no de cómo suceden las cosas, sino como si las cosas sucedieran de una determinada forma.

En esa forma de abordar la relación entre el individuo y el mundo se formula la noción de la verdad como lo útil ${ }^{7}$. La verdad guarda relación con la

1 «El mundo espiritual de la Antigüedad clásica se distingue de la Edad Moderna, en especial, en que es esta última la que ha alcanzado, por un lado, toda la profundidad y la plenitud del concepto de Yo - que se ha exacerbado en relación con el problema de la libertad, de importancia desconocida en la Antigüedad-y, por otro, también la autonomía y la fuerza del concepto de objeto, como se manifiesta en la idea de la inmutabilidad de las leyes naturales» (Simmel, 1977: 24).

2 Esta perspectiva la hereda Kant de Rousseau, quien desarrolló la idea de la capacidad de autogobierno del individuo y de que el deseo esclavizaba al individuo. Sólo el obrar independiente del deseo permite el autogobierno y la libertad del individuo.

${ }^{3}$ En Kant, la rectitud en el obrar se da allí donde la voluntad actúa independientemente de la naturaleza guiada por una legalidad interna. Esto constituye el deber, cuya objetivación es el derecho, mediante el cual se pone en relación la acción autónoma de los individuos, regidos bajo un orden de relaciones objetivas. Para Simmel, no será el derecho lo que configura el orden, sino el dinero.

${ }^{4}$ Simmel (1986) rechaza la concepción de Nietzsche como no moral, insistiendo en su similitud moral con Kant (p. 75).

5 Simmel (s.f.: 235).

${ }^{6}$ Vid. Simmel (1977: 537 y ss).

7 Vid. Simmel (1977: 86). 
organización y las formas de vida ${ }^{8}$. La verdad es una creencia necesaria que estabiliza la vida. El orden es superación de la incertidumbre. La calculabilidad es la expresión de ese orden, de la certeza. La verdad es condición de vida que no es dada naturalmente, sino a la que debe accederse y que tiene su anclaje en el mundo de la vida. El conocimiento es esquematización del caos, de acuerdo con las necesidades prácticas que pone la voluntad. Conocer no guarda relación con una supuesta teoría del conocimiento, sino con el poner orden. En el establecimiento de la verdad no existe más que el hecho de hacer que las cosas devengan calculables y manejables ${ }^{9}$. La verdad de las categorías radica en su condición de ser medio de vida para el sujeto. La inteligibilidad no alude al desvelamiento del sentido del mundo, sino a la manejabilidad del mundo por el sujeto. El sentido de lo que se hace inteligible nace del sujeto.

La puesta en el origen de la autonomía del yo excluye la noción de la acción del sujeto como acción causal, planteándola como acción teleológica orientada hacia un fin. La acción del individuo está determinada por el impulso, que puede o ser causa eficiente o ser "motivado" por un objeto exterior. En esta diferencia se sitúa la distinción entre acción causal y acción teleológica. En el orden teleológico, la voluntad aparece puesta en la orientación hacia una finalidad exterior al sujeto. En este impulso aparecen sucesivamente el sujeto y el objeto, aquél como el origen de la acción y éste como el punto de llegada, estableciéndose entre ambos una relación de reciprocidad.

Ambas formas de entender la acción están asociadas a diferentes concepciones del ser humano, que en un caso es naturaleza y en otro una realidad culturalmente construida. El hombre natural actúa de forma irregular e intermitente, buscando únicamente liberar «la fuerza nerviosa acumulada en los centros psíquicos» ${ }^{10}$. El hombre culturalmente determinado tiene un proceder metódico, a través del cual busca la recuperación voluntarista «de las resistencias que nuestro organismo opone al trabajo ${ }^{11}$. En esta diferencia subyace la distinción entre la noción providencialista del orden y la noción de orden constituido desde la subjetividad. El providencialismo del siglo XVIII identificaba el obrar del ser humano, la persecución de los propios intereses, como proyección de su naturaleza. La causalidad natural de su acción se reflejaba en la metáfora del mundo como un reloj. En este contexto la autonomía de la voluntad era despliegue causal de la naturaleza del ser humano. Kant, alejado

8 «Todos nuestros órganos —escribirá Nietzsche- y nuestros sentidos están desarrollados solamente con respecto a las condiciones de preservación y crecimiento. La confianza en la razón y en sus categorías, en la dialéctica, por consiguiente en la valoración de la lógica, únicamente prueba su utilidad para la vida, probada por la experiencia, no que algo sea verdad» (Nietzsche, 1968: fragmento 507).

9 Nietzsche (1968) lo había expresado así: «En la formación de la razón, la lógica, las categorías, fue la necesidad lo determinante: la necesidad, no "conocer", sino subsumir, esquematizar, con el propósito de la inteligibilidad y el cálculo» (fragmento 515).

10 Simmel (1977: 229).

11 Simmel (1977: 229). 
de esta concepción, pondrá el obrar específico del ser humano en el campo de la causalidad inteligible, y Nietzsche en la voluntad. La noción de voluntad en Nietzsche está alejada por completo de la concepción mecánica que la reducía a un movimiento que se originaba en la naturaleza ${ }^{12}$.

El hombre como naturaleza actúa a impulsos de su naturaleza. La libertad del individuo es la mera descripción, análoga a la de la lógica newtoniana, de su movimiento. El hombre determinado culturalmente aparece bajo otro prisma: no es su naturaleza, sino sus representaciones, las que determinan su acción ${ }^{13}$. Desde esta visión la noción del hombre utilitario, moviéndose por el placer y el displacer, ya no aparece como expresión de lo que es la naturaleza del ser humano, sino como una mera creación del espíritu humano.

La constitución de la sociabilidad como una proyección de la naturaleza queda definitivamente superada por la autonomía del yo. Al quebrase la relación necesaria entre la naturaleza del ser humano y una forma determinada de organización social, el origen aparece puesto en el yo autónomo. Esto pone fin a la filosofía clásica que concluía en el providencialismo. Con ello se pone la explicación de cómo se constituye el orden social sobre dos principios. Uno, que pondrá al sujeto como principio desde el que se constituyen las relaciones sociales, y el otro, la centralidad del poder como principio que explica esa constitución ${ }^{14}$.

En la distancia entre el hombre natural y el hombre culturalmente determinado se percibe una función diferente del pensamiento. La noción del hombre natural reduce el pensamiento a mera expresión de los intereses, de la naturaleza. La noción del hombre cultural pondrá el énfasis en la historia del espíritu humano como una dimensión que explica la forma de sus relaciones. El pensamiento adquiere relevancia como la forma en la que se expresa la naturaleza humana. El pensamiento, lejos de ser una mera superestructura, es un elemento que configura la propia naturaleza del ser humano.

El dinero aparece en un contexto en el que el deseo y su satisfacción son el horizonte vital del individuo. El dinero es el síntoma de que el hombre es un animal «que determina fines» ${ }^{15}$. Esta determinación tiene su origen en las representaciones mentales del individuo. Éstas hacen aparecer al dinero como un medio, como el medio por antonomasia, para alcanzar todos los objetos.

12 Caracterizando la noción de voluntad en Nietzsche, escribe Heidegger (1991): «Voluntario en sí mismo dominio sobre..., que se alarga más allá de ella misma; voluntad es intrínsecamente poder. Y poder es lo voluntario que es constante en sí mismo. Voluntad es poder; poder es voluntad. ¿No tiene, entonces, la expresión “voluntad de poder” sentido? Efectivamente, ninguno. Pero Nietzsche emplea, sin embargo, esta expresión en expreso rechazo de la forma usual de entender la voluntad, y especialmente en ordena enfatizar su resistencia a Schopenhauer» (vol. I, p. 41).

13 Weber lo expresará más adelante, señalando que las «ideas» dan lugar a imágenes del mundo que son las «vías por las cuales la dinámica de los intereses» mueve a la acción.

${ }_{14}$ Acerca de esto último puede verse Roberto González León (1996). Allí se muestra cómo la organización social basada en el cálculo monetario tiene su soporte en las relaciones de poder.

15 Simmel (1977: 237). 
Esta importancia como medio determina que su posesión sea el «centro de interés y el dominio real de aquellos individuos y clases cuya posición social los aísla de una serie de objetivos personales y sociales». El dinero adquiere en la conciencia del sujeto el carácter de fin, pues representa la posibilidad de relacionarse libre y autónomamente con el mundo exterior.

El dinero, que tiene su origen en el choque de voluntades entre individuos deseantes, se constituye en la forma que, independiente y autónoma respecto de las voluntades, rige el orden de las relaciones. El dinero subsume los objetos bajo la forma precio, colocándolos en un plano exterior y distinto del de las relaciones entre los individuos. Las cosas, representadas por el dinero, aparecen dotadas de un valor propio y, así, lo que originariamente tenía su origen en la relación y choque entre voluntades individuales, se alza como un plano compuesto de cosas que se relacionan entre sí. Esto pone de manifiesto el proceso de objetivación, en el que las representaciones originadas en el sujeto se independizan y aparecen como representaciones originadas en los objetos.

Originariamente, el valor surge de la convergencia entre el deseo del sujeto y la distancia respecto del objeto. El proceso de objetivación borra el rastro subjetivo del valor y éste, representado en el dinero, aparece como «supraobjetivo» $\mathrm{y}$ "supraindividual» ${ }^{16}$. El valor aparece, frente al sujeto, como resultado de la comparación entre objetos que en sus relaciones estructuran un mundo exterior en el que las cosas se determinan recíproca e independientemente de la subjetividad. En este proceso se delimita la separación entre el mundo del individuo y el mundo objetivo de las relaciones entre los objetos regidos por el dinero, sobre el que se despliega la técnica económica.

El dinero, como medio de objetivación, pone el choque entre voluntades en un plano exterior, permitiendo la relación ordenada y pacífica entre los individuos. Mientras que los objetos se presentan en sus cualidades, no permiten un intercambio tal que excluya los sentimientos subjetivos de desigualdad. Las propiedades del dinero hacen posible la equivalencia objetiva entre las prestaciones y las contraprestaciones. El objeto, subsumido bajo la forma precio, se integra en un proceso de intercambio que excluye cualquier sentimiento, vale decir cualquier rastro de relación directa ente individuos. La economía monetaria configura un orden calculable en el que la potencial conflictividad, derivada de la relación entre subjetividades, se disuelve en el orden objetivado de las relaciones entre las cosas. Emerge así la racionalidad social como un ámbito que excluye el sentimiento vinculado a las subjetividades. La exclusión de la violencia y del azar, así como el establecimiento de una relación de intercambio, percibida intersubjetivamente como objetiva, son la consecuencia de la generalización de la economía monetaria.

16 «En el intercambio, el valor pasa a ser supraobjetivo y supraindividual, sin que por eso llegue a constituir una cualidad y verdad objetiva de las cosas; aparece como aquella exigencia de las cosas — que va más allá de su objetividad inmanente- de no ser intercambiadas o conseguidas, sino es por medio de un valor correspondiente» (Simmel, 1977: 43). 
En este orden, el dinero pasa a medir todas las cosas «con objetividad despiadada» ${ }^{17}$. Esto determina la emergencia de "una red de contenidos vitales personales y objetivos que, en su entrelazamiento ininterrumpido y en su causalidad estricta, se aproxima al cosmos de las leyes naturales, cohesionada por el valor monetario que todo lo impregna, como la naturaleza lo está por la energía que todo lo vivifica y que, al igual que aquél, se reviste de mil formas y, a través de la regularidad de su esencia definitiva y de la transformabilidad de todas sus manifestaciones, vincula a todo, convirtiendo a todo en condición de todo lo demás» ${ }^{18}$. La medición "despiadadamente objetiva» del dinero subsume todos los contenidos vitales en un entrelazamiento que en su causalidad estricta los aproxima al cosmos de las leyes naturales. El dinero establece un orden de relaciones tras el que desaparece lo contingente, que emerge como un cosmos natural regido por la necesidad y cuya expresión son las leyes de la economía monetaria. El dinero cohesiona este cosmos, a la vez que lo impregna y dota de unidad ${ }^{19}$.

El dinero actúa como lenguaje $\mathrm{e}^{20}$. El lenguaje revela al individuo, por medio de la designación, la imagen del mundo y lo relaciona con él por medio de su función como instrumento de comunicación. En un modo análogo realiza el dinero su función. Las palabras, como el precio en dinero, son los signos de las cosas. El dinero, como el lenguaje en su función instrumental, es el medio de la relación del sujeto con las cosas exteriores a él.

Debido a su forma, el dinero es «el representante más acabado de una tendencia epistemológica de la ciencia moderna en general: la reducción de las determinaciones cualitativas a las cuantitativas» ${ }^{21}$. En el cumplimiento de esta tendencia todo aparece ordenado según número y medida del número, y las diferencias cualitativas transformadas en diferencias cuantitativas. Se borra toda determinación cualitativa en las cosas y emerge la cantidad como lo único relevante. Este despliegue de lo cuantitativo tiene como consecuencia el que la cantidad es la única representación de las cosas. Con la generalización de la economía monetaria, este proceso alcanza su punto más extremo y definido, apareciendo como "el punto más elevado de un orden de evolución histórico espiritual que determina inequívocamente su orientación» ${ }^{22}$.

La autonomización de la circulación monetaria permite subsumir el proceso de intercambio, y las relaciones que subyacen, a la lógica matemática, haciendo posible que la tendencia epistemológica hacia lo cuantitativo abarque el ámbito de las relaciones sociales. El dinero, en su capacidad de representar la totalidad de lo cualitativo bajo la cantidad, hace posible integrar el proceso de

7 Simmel (1977: 539).

18 Simmel (1977: 540).

19 En su forma técnica, «la circulación económica crea un reino de valores que se independiza más o menos completamente de su infraestructura subjetiva y personal».

20 Simmel (1977: 213).

21 Simmel (1977: 328).

22 Simmel (1977: 332). 
intercambio en lo que el pensamiento moderno considera como conocimiento científico y que encuentra en la expresión matemática su forma más acabada. En esta representación lo espontáneo e imprevisible no tiene cabida. Todo se relaciona a partir de principios fijos de extensión y movimiento, llevando al campo de las relaciones sociales uno de los supuestos fundantes del pensamiento moderno: el que todos los elementos guardan relación entre sí y lo hacen según determinados principios.

Lo matemático se apoya en la representación de las cosas por el dinero. Como Heidegger señaló, lo característico de lo matemático es que revela cosas que ya son conocidas, pues sustituye las cosas manifestadas en su naturaleza por unidades. En cuanto unidades, cosas de naturaleza diferente se pueden relacionar entre sí y establecer un vínculo común. Lo matemático es una extensión de la subjetividad que primero se proyecta sobre lo conocido y posteriormente dice de él algo que el sujeto conoce ${ }^{23}$. El conocimiento matemático es independiente de los objetos. El número, subsumido en lo matemático, no pertenece a la naturaleza de las cosas, sino a la naturaleza de nuestra subjetividad. Lo matemático anticipa, como conocimiento axiomático, la esencia de las cosas y las presenta distribuidas en una superficie homogénea desprovista de cualidades.

Lo matemático y la circulación monetaria son formas análogas. Uno y otra se establecen en oposición a la oscuridad y confusión de la subjetividad, presentando las cosas bien bajo el número o bajo el precio, en forma clara y distinta. Lo claro y lo distinto es el rasgo que caracteriza la concepción moderna del conocimiento, que cifra su horizonte en la exactitud, a la que se accede reduciendo la complejidad a la más extrema simplicidad. Esta percepción de lo claro y distinto es incompatible con los sentidos; sólo el entendimiento permite esta percepción. Con la retirada de la sensibilidad, lo claro y distinto configuran un mundo uniforme en el que las cosas se diferencian nítidamente en su cantidad. La realidad cualitativa, representada en una primera instancia por los objetos, tras los que subyacen individuos que se relacionan con otros individuos, se reduce, en la representación, a una relación entre masas homogéneas. La economía monetaria es la descripción del movimiento de estas masas regidas por la ley universal de la oferta y la demanda.

Mediante el lenguaje matemático se describe la objetividad que compone el mundo exterior al individuo. La sustitución del lenguaje natural, caracterizado por su equivocidad, por el lenguaje unívoco y artificial de la matemática realiza la «objetividad despiadada» de dinero, a partir de la cual la red de contenidos vitales se uniformiza en un conjunto de puntos regidos por la lógica. La subjetividad que regía el mundo premoderno, encarnada en la voluntad del príncipe o del ciudadano, es sustituida por la objetividad calculable e indiferente.

23 "Lo matemático es esto "acerca" de cosas que ya conocemos realmente. Por consiguiente, no lo alcanzamos primero por las cosas, sino en cierto sentido, lo llevamos ya con nosotros» (Heidegger, 1993: 276). 
El análisis de Simmel se sitúa fuera del ámbito de la filosofía clásica, que había establecido la disolución de la autonomía del sujeto a la vez que lo ponía en el centro metódico de la reflexión. Este planteamiento se movía en un círculo que, partiendo de la autonomía del sujeto, terminaba en su completa determinación exterior ${ }^{24}$. Esta inversión que pone al sujeto en el centro del conocimiento se acompaña, a su vez, de la pérdida de autonomía. Esta peculiar relación es visible en Descartes, quien, por una parte, privilegia desde un punto de vista metodológico el conocimiento reflexivo. Pero, por otra parte, este conocimiento reflexivo presupone una doctrina metafísica «que tiende a abolir la actividad autónoma del yo» ${ }^{25}$. El providencialismo es la continuación de esta relación. Esto cierra el análisis en torno a la rígida determinación de la acción del individuo, cuya consecuencia es la falta de libertad del ser humano.

La representación exterior del mundo regido por el dinero es la proyección de un rasgo característico del espíritu humano, la capacidad de objetivar. El espíritu humano evoluciona en el sentido de una «separación cada vez más fundamental y más consciente entre las representaciones objetivas y subjetivas, que, en principio, se mueven en una situación psicológica poco clara y bastante indiferente» ${ }^{26}$. La historia del espíritu humano es el despliegue del proceso de objetivación, cuyo significado es que la originaria identidad entre el ser humano y los objetos se irá escindiendo hasta alcanzar la mutua independencia.

Simmel, en la estela de Kant y Nietzsche, establece la constitución del orden como una derivación del sujeto, que guarda relación con su capacidad de objetivar. Al escapar a las consecuencias del determinismo anterior, Simmel describe la escisión entre la personalidad libre y la función articulada respecto de otras funciones. El dinero establece este orden objetivo de relaciones. El mundo ya no aparece como una imposición de la providencia y de determinaciones exteriores.

La consecuencia del proceso de objetivación es la emergencia del rasgo fundamental que caracteriza a la sociedad moderna: la disociación entre la personalidad y la función. La personalidad es el espacio del yo, que se proyecta como despliegue del deseo y cuya realización depende únicamente de su decisión autónoma. La personalidad es independiente de otras personalidades, puesto que las relaciones sociales se articulan a partir de las funciones. La complejidad del mundo regido por el dinero intensifica el desarrollo de la división del trabajo y, como consecuencia, la interdependencia entre los individuos, a la

24 Muralt (1985) describe este proceso al señalar que en la filosofía clásica el sujeto del conocimiento «tiende a perder el dinamismo de su propio ejercicio, en provecho de una determinación eficiente y formal de la omnipotencia divina» (p. 147).

25 Muralt (1985: 147).

26 Simmel (ob. cit.: 402). 
vez que estas relaciones son establecidas fuera del ámbito personal: «La división moderna del trabajo aumenta el número de dependencias en la misma medida en que hace desaparecer a las personalidades detrás de sus funciones» ${ }^{27}$. Éstas constituyen un orden jerárquicamente establecido respecto de fines que no son de naturaleza personal, sino técnica. La jerarquización de las funciones pertenece al ámbito separado por completo de la personalidad, que se sitúa en un orden de igualdad, indiferencia y autonomía. La personalidad aparece como "contraposición y complemento de la objetividad»" ${ }^{28}$. Esta relación entre el yo y las cosas se inscribe en un contexto en el que «cada vez aparece con mayor claridad y exactitud el carácter de la naturaleza sometida a leyes, el orden objetivo de las cosas, la necesidad objetiva del acontecer y, por otro, cada vez se acentúa de modo más intenso y poderoso la individualidad, independiente, la libertad personal y el ser-para-sí frente a todo lo exterior y a todas las fuerzas de la naturaleza ${ }^{29}$. La extensión de la economía monetaria desarrolla la reciprocidad mutua entre los seres humanos a la vez que se disuelven los elementos personales en las relaciones entre los individuos. Esta disolución es la condición de la interdependencia mutua, de la que el dinero es el vehículo adecuado puesto que, a la vez que crea relaciones entre los seres humanos, «deja a las personas fuera de ellas» ${ }^{30}$. La organización social se despliega como un orden objetivo de funciones separadas respecto de la personalidad. Este orden se objetiva frente a la personalidad como algo exterior a ella.

Este proceso de constitución de las relaciones sociales como relaciones entre funciones, relacionadas a su vez por el dinero, y no como relaciones entre personalidades, viene a replantear el problema de la organización social tal y como fue concebido por el pensamiento del siglo XVIII. El temor a la muerte, explicó Hobbes, empuja a los individuos a un pacto en el que se desprendían de su libertad para constituir la paz social. Otra forma de limitación aparece en la noción del ser humano empujado a relacionarse con los demás como único medio, a través de la división del trabajo, para satisfacer sus necesidades y de$\operatorname{seos}^{31}$. Tanto la seguridad como la satisfacción del deseo empujan al individuo a subordinarse a un orden externo. En ambos casos aparece la contraposición entre la autonomía y libertad del individuo y la constitución del orden social. El individuo libre aparece o sometido a la amenaza de los otros o incapaz de satisfacer sus necesidades. La renuncia a la libertad, bien bajo la égida del Leviatán, bien bajo el disciplinamiento que impone la división del trabajo, es la condición que permite la seguridad y la satisfacción de las necesidades, respectivamente.

El análisis de Simmel muestra cómo en el mundo moderno esta relación se

27 Ibid.: 354.

${ }^{28}$ Simmel (1977: 362).

29 Simmel (1977: 362).

30 Simmel (1977: 363).

${ }^{31}$ Esta concepción fue desarrollada por Hutcheson (1969) y se constituyó en el origen de la economía política clásica. 
presenta bajo otro prisma, en el que la libertad y la autonomía del individuo son paralelas a la constitución del orden social. Esta nueva presentación de la posición del individuo lleva consigo la caracterización de la libertad del individuo asentada en la personalidad escindida de la función. En la extensión de la economía monetaria es donde se materializa esa duplicación. Lo característico de su análisis es la convergencia entre la máxima libertad y autonomía del individuo y la máxima formalización, autonomía e independencia de las relaciones sociales.

En el mundo moderno, la libertad y la autonomía se expresan mediante el dinero y su constitución como exclusivo vínculo entre individuos y cosas. Respecto de la personalidad, la posesión del dinero es la medida de la independencia, libertad y autonomía. Respecto de las funciones, el dinero es el principio que rige autónomamente sus relaciones. La tecnificación de lo exterior al individuo, del orden compuesto por las relaciones entre funciones, excluye la arbitrariedad y el azar e introduce la seguridad y la calculabilidad. En esa configuración de lo exterior, de lo sociable, de un modo análogo a lo natural, el individuo se ubica estable e independientemente respecto de otros individuos.

Para Simmel, es el dinero, y su generalización en la economía monetaria, lo que explica la constitución social y que a la vez es simétrica con la plena autonomía y libertad de la personalidad. En su planteamiento, el ser humano aparece bajo un prisma ambivalente. Es libre e independiente de la voluntad de otros seres humanos, pues el dinero le otorga la posibilidad de un obrar autónomo. Esto implica que la única relación del ser humano lo es con los objetos. El proceso de objetivación que hace posible la independencia respecto de los demás y la relación exclusiva con las cosas ilustra sobre la peculiaridad de la moderna sociabilidad: que ésta no tiene su origen en los individuos, sino en las cosas.

La orientación hacia el dinero y el acrecentamiento del poder del ser humano sobre la naturaleza "refuta la opinión de que el mundo ya está repartido y que no condiciona la satisfacción de las necesidades, a ningún tipo de robo» ${ }^{32}$. La posibilidad creciente de satisfacer las necesidades, junto a la extensión de la autonomía y libertad individual, ratificada por el derecho, constituye "el progreso sustancial de la cultura». Este proceso es una consecuencia de la capacidad de objetivación del espíritu humano.

En el distanciamiento respecto de los objetos radica la posibilidad de dulcificar "la tragedia humana de la competencia» ${ }^{33}$, puesto que cuando las cosas aparecen puestas en ámbito de lo objetivo, el acceso a ellas, por medio del

32 Simmel (1977: 346).

33 «La única moralización posible se da a través del proceso cultural que cada vez objetiva más contenidos vitales en formas transindividuales: los libros, el arte, las construcciones ideales como la patria, la cultura universal, la configuración de la vida en imágenes conceptuales y estéticas, el conocimiento de miles de cosas interesantes y significativas, todo esto se puede disfrutar sin que no haya que quitárselo al otro» (Simmel, 1977: 347). 
dinero, no implica la violación de la autonomía y libertad del otro. La disociación del yo y la objetividad permite «la construcción de un mundo que es apropiable sin lucha y sin opresión mutua, a la formación de valores, cuya consecución y disfrute por parte de una persona no excluye a la otra, sino que, antes bien, abre el camino al otro" ${ }^{34}$. Por el desarrollo de su capacidad de objetivación, el deseo, móvil de la acción del individuo, no lleva a éste a la confrontación inmediata con otro, sino que lo refiere únicamente a los objetos. La lucha de todos contra todos se transforma, por la capacidad de objetivación, en la convergencia pacífica, mediada por el dinero, sobre los distintos objetos.

Este modo de relación escindida es el modo de organización de las relaciones sociales, en las que no está implicada la personalidad, sino la función que el yo realiza. La anterior relación en la que el yo está determinado se transmuta en una relación de igualdad entre personas y de jerarquización entre las funciones. Describiendo esta última relación, escribe: «El jefe de producción y el trabajador más inferior, el director y el vendedor de unos grandes almacenes, están sometidos a un fin objetivo común y, dentro de esta relación general, subsiste la subordinación como necesidad técnica en la que se expresan las exigencias de las cosas y de la producción como un proceso subjetivo» ${ }^{35}$. La finalidad que estructura la jerarquía de las funciones no aparece como una imposición arbitraria de una voluntad, sino como un requerimiento de naturaleza técnica. La jerarquía ya no encadena personas, sino funciones. El yo aparece liberado de la voluntad arbitraria del otro y en su lugar se pone la función. Esta sustitución termina por desvanecer todos los sentimientos de agravio entre las personas ${ }^{36}$. Los individuos son reconocidos como iguales que realizan funciones diferentes ${ }^{37}$.

La escisión entre la persona y la función ocupa el centro de la forma moderna en la que se ordenan las relaciones sociales. La persona se cierra sobre sí misma, mientras que la función estructura la organización de las relaciones sociales. La extensión de la economía monetaria hace posible esta duplicidad, que se constituye en el rasgo característico de la sociedad moderna. La estructura de las funciones y su disposición jerárquica es compatible con la noción de sociedad compuesta por personas libres y autónomas ${ }^{38}$.

${ }^{34}$ Simmel (1977: 347).

35 Simmel (1977: 406).

36 Simmel (1977: 409).

${ }^{37}$ Simmel subraya la extrema importancia de esta duplicidad entre igualdad personal y diferencia entre funciones, "porque toda la experiencia que hasta ahora hemos tenido muestra que la superioridad y la subordinación son medios absolutamente imprescindibles de organización y que, con ellos, desaparecería una de las formas de producción social más fructíferas. La tarea es, por lo tanto, conservar la jerarquía, en la medida en que tiene consecuencias y, al mismo tiempo, vencer los resultados psicológicos por cuyo motivo se rechazan» (Simmel, 1977: 408).

${ }^{38}$ En esta disociación se encuentra el origen de la sociología como descripción de los roles sociales. La función permite la caracterización de la acción como un proceso lógico, que elimina lo contingente y permite establecer un sistema de relaciones necesarias. 
En esta separación se delimita el perímetro de la personalidad respecto de la función. La personalidad abarca el ámbito del yo, mientras la función alude a la acción del ser humano en relación a lo exterior. Entre las funciones, el dinero es el único elemento de mediación, a la vez que la personalidad se "diluye por completo en las condiciones de la economía monetaria»" Las relaciones establecidas entre las funciones, basadas exclusivamente en la posesión de mercancías y la prestación de servicios, excluyen a la personalidad. En la relación que se establece en el exterior no aparece la personalidad del otro, sino únicamente el contenido de su función. La persona no se encuentra sometida a una lógica exterior, sino la función. La distancia entre uno y otro es la esfera de la libertad de la persona. El orden de las funciones se tecnifica, se despoja de cualquier arbitrariedad frente a la persona.

La personalidad es indiferente tanto a la función como al orden exterior que compone. La completa disociación respecto del exterior es el contenido de la autonomía de la personalidad, que aparece así caracterizada negativamente, como independencia respecto de lo que es exterior a ella. Lo exterior es una estructura de funciones que únicamente tiene que ver con el intercambio monetario de mercancías y servicios. La personalidad está ausente de la función.

En esta misma disociación la personalidad aparece separada de otras personalidades. La relación que el yo establece lo es exclusivamente con los objetos a través del dinero, y con el otro a través de las funciones. En la relación que la persona establece con la función pierde su carácter y pasa a ser definida desde los caracteres adscritos a la función. En la transición desde el yo a las funciones se produce el vaciamiento del yo real y su sustitución por el yo de la representación. En esta separación se realiza la autonomía de la personalidad. El ser humano aparece entrecruzado por la paradoja, pues en cuanto persona es autónomo y en cuanto función es heterónomo.

La historia que desemboca en la modernidad es relatada por Simmel como un proceso a lo largo del cual se transforma la relación entre el yo y el otro. Originariamente, esta relación se ponía en términos de obligación en la que estaba implicada la dependencia personal.

La función del derecho, como muestra Simmel, conduce a la independencia entre el ser del yo y aquello que le rodea. En las formas premodernas del derecho, la obligación invade la libertad de la persona. Son aquellas formas en las que «el derecho del señor se extiende inmediatamente a la personalidad del que presta los servicios» ${ }^{40}$. El extremo opuesto es aquel en el que el derecho se extiende exclusivamente al producto, con independencia del trabajo que se haya desarrollado ${ }^{41}$. En esta forma del derecho, la personalidad y la obligación

39 Simmel (1977: 354).

40 Simmel (1977: 338).

${ }^{41}$ La servidumbre, la limitación de los servicios y su desvinculación respecto de la persona son las sucesivas transiciones hacia la autonomía del que está sometido a una obligación. 
están completamente separadas. El dinero, como sustitución de la prestación personal, impulsa estos cambios. La generalización de la economía monetaria rompe la relación entre las personas, a la vez que subsiste la relación de obligación. El derecho en una sociedad regida por la economía monetaria se despliega como un conjunto de normas que fijan el ámbito en el que se desarrollan las relaciones entre las personas. Las obligaciones no son tipificadas como relaciones entre personas, sino entre las funciones en las que las personas exteriorizan sus acciones. El derecho fija las condiciones en las que se despliega el dinero. El reconocimiento de la propiedad privada, así como la inviolabilidad de la persona, son las condiciones que hacen posible la disociación entre la persona y la función y entre las personas.

El orden de las funciones compone el sistema de las relaciones sociales. Éstas aparecen relacionadas por el dinero, que determina su orden. La lógica de las relaciones sociales aparece, en último término, determinada por la lógica de las relaciones monetarias. El orden de las funciones, y por tanto el sistema de relaciones sociales, se inscribe en un universo autónomo sustraído a toda arbitrariedad, pues las leyes del dinero aparecen como técnicamente determinadas. En la medida en que la arbitrariedad, es decir, lo político como voluntad, está excluida, aparece garantizada la libertad del individuo.

La noción de orden que describe Simmel es análoga a una estructura funcionarial, desplegada como un orden de funciones, en el que está disociada la posición de los rasgos del individuo que la ocupa. El carácter y la personalidad del individuo son indiferentes a la acción que se realiza desde la función ${ }^{42}$.

La disociación entre la personalidad y la función es la condición de la libertad moderna. El yo encerrado en el perímetro de la personalidad es independiente de la función exterior que cumple. El ser íntimo, el ser uno para sí mismo, aparece rodeado de una suerte de muralla que lo separa de los otros seres. Las relaciones externas entre las funciones dejan fuera ese yo íntimo. Es una doble escisión la que se produce: entre las personas y la persona y el mundo. La consecuencia es la emergencia de la individualidad autónoma, que encuentra en la preservación de su aislamiento el ideal de vida en libertad.

La proyección del actuar del sujeto teleológicamente determinado cristaliza en una realidad escindida en la que el yo permanece como personalidad inde-

${ }^{42}$ La disociación entre individuo y función, característica del orden burocrático, tiene un origen que se remonta al siglo XIV. La subsunción del individuo a la función es descrita como una consecuencia de la noción de la Iglesia como organización independiente de la temporalidad de los individuos que la componen. Nicolás de Cusa (1991) desarrolló esta separación estableciendo que la validez de las acciones dependía de la función desde la que se ejercía. La cualidad de las personas es indiferente al cumplimiento de las acciones: «Por consiguiente un mal ministro no hace daño, pues el Espíritu Santo actúa a través del prelado» (p. 19). El individuo es un mero agente de la función. Esta subsunción en la función la autonomiza frente al devenir y la temporalidad de los individuos. Es la primacía de la Iglesia, de la relación objetivada, en la que la condición del ser humano es irrelevante. De ese modo, «aunque una persona perniciosa pueda a menudo sentarse en la cátedra episcopal, la verdad enseñada por el ejercicio de la cátedra es infalible por esta razón» (p. 31). 
pendiente de los demás. La simetría entre la libertad del yo y la libertad del otro se hace posible en el aislamiento. El dinero determina que las acciones de los individuos se manifiesten en fines expresados monetariamente. La objetivación del orden teleológico es la condición que unifica las funciones y mantiene separadas a las personalidades. El dinero es la transmutación del valor que desde el sujeto se impone a la naturaleza y la ordena.

La técnica económica, como gestión de la economía monetaria, surge de este proceso de evolución del espíritu humano. La escisión entre el sujeto y el objeto supone la desvinculación de los intereses personales del proceso económico. Los intereses funcionan como si fueran fines en sí mismos, mientras que el proceso económico lo hace como un proceso mecánico cada vez «menos influido por las irregularidades y las sorpresas de los elementos personales ${ }^{43}$. En esta separación se dibuja la duplicidad entre lo subjetivo y lo objetivo, como esferas autónomas e independientes. Los intereses constituyen fines en sí mismos para el individuo, que los confronta y trata de realizar en un orden mecánico del que está excluida cualquier interferencia originada por otros intereses.

La separación que la economía monetaria establece entre la objetividad y el yo independiza a ambas instancias. La completa separación y objetivación de la economía se hace manifiesta allí donde «realiza su función según fuerzas y normas que no son idénticas a las de su propietario, sino relativamente independientes de éste» ${ }^{44}$. El dinero y el yo que lo posee son libres en cuanto separados el uno del otro. La norma del dinero, en cuyo desenvolvimiento está excluido el otro, hace a su propietario independiente respecto de los demás en su acceso a los objetos.

La distinción entre la personalidad y la función resuelve el dilema de la insociabilidad de la naturaleza humana. La libertad queda confinada a la personalidad separada del exterior, configurado como un orden de relaciones entre funciones, sujeto a una legalidad propia. La acción de la personalidad aparece sobrevolada por la fatalidad que rompe la relación entre las intenciones y las consecuencias. El proceso de objetivación cierra al ser humano, libre en un mundo determinado, cuya manifestación más sintomática es que las intenciones aparecen desvinculadas de sus consecuencias. Las intenciones permanecen en el perímetro de la conciencia. Mediante prueba y error, el individuo puede ajustar sus actos a la única intención cuyas consecuencias puede determinar: la persecución del propio interés ${ }^{45}$. La génesis de esta desvinculación se remonta a las fórmulas derivadas de la hipótesis occamista ${ }^{46}$, cuya consecuencia fue la desvinculación de la intención del ser humano, la salvación, de las consecuencias de sus actos. Un acto únicamente es juzgado por Dios como mere-

43 Simmel (1977: 403).

44 Simmel (1977: 405).

45 A esto alude Hayek con su formulación sobre las consecuencias no queridas de la acción.

${ }^{46} \mathrm{La}$ influencia de la hipótesis occamista sobre el pensamiento político moderno ha sido desarrollada por Muralt (1978). 
cedor o no de salvación. El mundo secularizado borra la figura de Dios y coloca en su lugar la exterioridad objetivada. Ésta continúa, no obstante, siendo tan opaca a la razón humana como antes lo era la voluntad divina. El yo es el único punto de partida, pero ahora desvinculado de esta exterioridad. Análogamente a como sucede con la salvación, las consecuencias de la acción no guardan relación con la intención.

La libertad y autonomía del individuo se caracteriza en términos negativos. Es distancia respecto de los demás. La satisfacción del deseo, independientemente de los otros, es la manifestación de la libertad. El dinero, al establecer la relación exclusiva ente el yo y los objetos, hace posible esa distancia. La posesión del dinero independiza a la persona respecto de otras personas, transformando la satisfacción del deseo en un acto autónomo e independiente. En la penumbra permanece lo que significa la distinta posesión del dinero. Ésta establece la diferencia en cuanto al acceso a la satisfacción del deseo. Pero es una diferencia que no se objetiva en una relación jerárquica y permanece irrelevante frente a lo que resulta relevante: la igualdad entre todos los individuos en su libertad e independencia.

La unificación de los bienes y su producción en el dinero abre el camino a la independencia de los individuos entre sí: "cuando los individuos se concentran en el dinero y la propiedad consiste en dinero, el individuo tiene que adquirir la tendencia y el sentimiento de una significación autónoma frente a la totalidad social y ha de comportarse frente a ésta como un poder en relación con otro, puesto que está en libertad de buscar donde quiera sus relaciones de negocio y cooperación ${ }^{47}$. El dinero disuelve las relaciones de comunidad ${ }^{48} y$ refuerza la individualidad. El dinero abre el camino hacia la sociedad abierta, desarrollando aquellas formas de organización social «que unifica lo impersonal en los individuos en favor de una acción y que nos ha proporcionado la posibilidad de aprender cómo las personas pueden unirse con reserva absoluta de todo lo personal y específico» ${ }^{49}$. El dinero "nos hace libres» a la vez que resuelve la paradoja de la individualidad deseante y su relación con otras individualidades semejantes. Esta relación se resuelve en el mantenimiento de la individualidad deseante y la libertad y autonomía del individuo.

En el planteamiento de Simmel sigue presente un rasgo peculiar del modo como el individualismo aborda la explicación de cómo se constituye la sociabilidad. Este rasgo alude a la imposibilidad de concebir las relaciones sociales como un orden derivado de la relación inmediata entre los seres humanos. Esta relación sólo es concebible mediada o por un poder exterior a por la norma. Lo que aquí subyace es la noción de que la inmediatez en la relación entre los seres humanos implica su destrucción ${ }^{50}$. La voluntad del Leviatán, las leyes de

47 Simmel (1977: 417).

${ }^{48}$ Como Tönnies describirá en Comunidad y Asociación.

49 Simmel (1977: 421).

${ }^{50}$ Nietzsche representa este dilema en las figuras del hombre dionisíaco y el hombre apolíneo. El primero es el ser reconciliado con los otros y con la naturaleza, pero a la vez confrontado 
la economía política y el derecho, fueron formas sucesivas de explicar el nacimiento de la instancia exterior que media entre los individuos y los integra socialmente.

La economía monetaria establece un sistema de relaciones en las que se hace compatible la libertad del individuo con la seguridad y el cálculo. La exigencia de seguridad se encuentra en los orígenes de la explicación moderna de la sociabilidad. El Leviatán, al imponer su voluntad, introduce la seguridad en las relaciones entre los individuos. Las leyes de la economía política clásica pretendían describir los mecanismos objetivos para la distribución de la riqueza generada por la división del trabajo. La teoría subjetiva del valor pondrá en la figura del consumidor, actor racional que calcula en términos monetarios, y su relación con las cosas, regladas por el precio, el principio de orden.

En los tres casos se apunta hacia lo mismo: la constitución de un sistema objetivo de relaciones entre individuos, exterior a ellos. En la exterioridad de estos órdenes se desvanecen las cualidades de los individuos, su subjetividad diferenciada, reapareciendo como cantidades iguales, libres, autónomas, independientes e intercambiables. La economía monetaria, la objetivación que supone, intensifica la separación entre los individuos, en cuanto que todos ellos exteriorizan sus acciones como resultado del cálculo monetario, generalizándose la calculabilidad y reduciendo la incertidumbre de la mutua relación entre los seres humanos.

En la generalización de la economía monetaria se pone de relieve la forma en la que se alcanza la seguridad y cómo ésta tiene como condición el completo alejamiento respecto del otro. En la seguridad que proporciona el orden objetivado, el individuo maneja y calcula sus relaciones con el exterior. En esta relación no hay incertidumbre, pues lo exterior deviene completamente inteligible. En este contexto, hacer inteligible el mundo no significa el desvelamiento de la verdad de su estructura exterior, sino con el cálculo y manejo de lo exterior, lo que remite a una noción exclusivamente formal de la racionalidad ${ }^{51}$. En la constitución del orden social por medio de las relaciones entre las cosas, se resuelve el conflicto entre individuos regidos por el deseo. La mediación del dinero permite la constitución del orden. La noción del ser humano como ser deseante fue vista, en el siglo XVIII, como la raíz de la conflictividad de la relación inmediata entre los individuos.

El deseo y su realización en libertad e independencia se constituye en el horizonte de la acción del individuo. El ser humano es subsumido en la figura del consumidor, que en la medida que acrece y satisface su deseo experimenta mayor libertad. Este acrecentamiento de la libertad conlleva la radicalización

con el terror de la muerte, que hace de él una figura embriagada. Su opuesto es el hombre apolíneo, representación del individuo sometido a la norma.

${ }^{51}$ En el paso desde una a otra noción de inteligibilidad se inscribe la crisis de la teoría clásica del valor trabajo. La determinación objetiva, por el trabajo, del valor de las cosas determinaba que éstas se ordenaran según sus distintos valores, independientemente de las voluntades. 
de la relación instrumental entre el yo y el mundo. Lo exterior, que incluye a la naturaleza y a los demás, aparece única y exclusivamente como algo a explotar, algo puesto al servicio del deseo, pues esto contribuye a «atraer más materias y fuerzas hacia nuestras formas racionales y anexionarlas». Lo exterior es lo explotable, numero estar ahí al servicio del deseo, que aumenta indefinidamente la producción de objetos. La contraposición entre el mundo humano y el mundo natural es el rasgo constitutivo de la civilización. Pero esta contraposición hay que verla bajo el prisma de la individualidad que establece su contraposición con el exterior. Así, el mundo humano aparece reducido al perímetro del yo, y el mundo exterior, que incluye a los otros y a la naturaleza, como objeto de explotación ${ }^{52}$. Y es que la subjetividad aparece en el mundo moderno cerrada sobre la individualidad, de tal modo que para una subjetividad otro individuo pertenece al mundo de los objetos.

El consumidor deviene el centro de la organización del proceso social ${ }^{53}$. Esta centralidad es el contenido del giro del pensamiento económico a mediados del siglo XIX. El consumidor aparece como un ser racional, dotado de autonomía y libertad. Con su emergencia se delimita la frontera entre la economía clásica y la economía neoclásica, entre la teoría objetiva del valor y la teoría subjetiva del valor, entre una sociedad compuesta por individuos agrupados en clases sociales y una sociedad compuesta por individuos iguales e intercambiables. Esta transición viene determinada por la generalización de la división del trabajo, el proceso de intercambio y la intervención del dinero, cuyo resultado es la aparición de la riqueza abstracta o el dinero como el motivo de la producción, revelando que el motivo real de la producción son las necesidades y deseos de los consumidores. Las demandas de los consumidores determinan las mercancías proporcionadas por los productores ${ }^{54}$. El consumidor es la representación del individuo libre que ocupa el centro de la organización de la producción.

En este giro desaparece todo rastro de teología representada por la metáfora de la mano invisible. Ahora quien actúa como principio de organización de

52 Schopenhauer puso el origen del egoísmo en la misma representación que el ser humano tiene del mundo exterior. Como noción teórica, el egoísmo consiste en negar realidad al mundo exterior. Como noción práctica consiste en verse a uno mismo como persona real, mientras que los otros son considerados como fantasmas. El egoísmo establece una radical separación entre la propia persona y lo que es exterior a ella. El yo se considera el centro del mundo y todo lo demás como existente en función del yo. El egoísmo nace de la forma en que el ser humano ve el mundo empírico. Su nacimiento se sitúa en la confusión entre el orden de la representación, el mundo empírico, y el mundo en sí, la naturaleza. El resultado es que el ser humano cree que sólo existe en su propia persona y no en los demás. Desde el mundo de la representación, la existencia se le aparece al individuo como la lucha de todos contra todos.

53 Mises (1985) dará cumplida cuenta de esa centralidad: «No hay en el sistema de la sociedad de mercado otro medio de adquirir riqueza y conservarla que atender con éxito las necesidades de los consumidores» (p. 240). El consumidor «dirige» el sistema de la producción en la sociedad de mercado (vid. p. 285).

54 Vid. C. Leslie (1876). 
las relaciones sociales es el individuo en su función de consumidor ${ }^{55}$. Superada la teología, es la acción del individuo como consumidor la que «asigna a cada uno su lugar en la sociedad $»^{56}$. La armonía de intereses ya no tiene su origen en la acción causal del individuo, bajo la égida de la mano invisible, sino en la figura del individuo que se relaciona con las cosas impulsado por su deseo, por medio del cálculo monetario. El consumidor es la omnipresente figura que determina todo aquello que acontece ${ }^{57}$. La sociedad moderna aparece como una organización democráticamente regida por el consumidor ${ }^{58}$.

La figura del consumidor pone en el individuo el principio de constitución de la organización de la producción. La economía política clásica había descrito las leyes que subsumen el comportamiento causal de los individuos. En oposición a esto, la figura del consumidor pone en la autonomía y libertad el principio constitutivo del orden social. No hay leyes, sino individuos que actúan libre y autónomamente en el contexto de las determinaciones de la economía monetaria. Con la desaparición del providencialismo emerge la contingencia, que a su vez se encuentra cruzada por la necesidad que nace de la calculabilidad y la manejabilidad. En este cruce emerge una noción del orden que ya no es la que regía la mano invisible, sino que está determinada por el grado en el que el mundo aparece determinado por el grado en el que aparece como calculable, desde la libertad y la autonomía del individuo ${ }^{59}$.

Simmel coloca el mundo ocupado por el individuo autónomo, representado bajo la figura del consumidor en la emergencia de entendimiento como expresión única de la energía espiritual. Esta forma de energía responde a las manifestaciones de la economía monetaria. En oposición al entendimiento se sitúa el sentimiento, que es la manifestación de la energía espiritual en aquellos períodos no determinados por la economía monetaria. En la modernidad, la consecuencia es la desaparición de las manifestaciones sentimentales, sustituidas «por una inteligencia objetiva» ${ }^{60}$. El mundo se transforma en obje-

55 Mises (1985) escribirá: «Ser rico, en pura economía de mercado, es el resultado del éxito de servir mejor las demandas de los consumidores» (p. 286).

${ }^{56}$ Mises (1985: 291).

57 «En el mercado todo el poder está en las manos de los consumidores» (Mises, 1985: 683).

58 Mises (1985: 856).

59 A partir de esto se describirá la acción racional como aquella que es conducida «sobre la base de los cálculos en moneda» (Mises, 1985: 248). Sentada esa racionalidad se puede construir una ciencia de la acción humana, que se configura como una "teoría de todo actuar humano, la ciencia general de las categorías inmutable desde la acción y de su funcionamiento bajo todas las condiciones particulares en las que el hombre actúa" (Mises, 1985: 282). La ciencia de la acción se distancia tanto del historicismo como del positivismo. Respecto de este último señala Mises la ficción que supone someter la acción a una legalidad similar a la que describió Newton para el mundo físico. Esto constituye la cataláctica, la ciencia de los medios para la realización mediante el cálculo monetario de los fines elegidos. La acción humana se hace observable allí donde aparecen los resultados del cálculo monetario. La finalidad de la acción, aquello hacia lo que se dirige el deseo, cae fuera de toda consideración racional. La racionalidad está circunscrita exclusivamente al momento del cálculo, a la adecuación de las operaciones.

${ }^{60}$ Simmel (1977: 540). 
to de la inteligencia y el sentimiento deviene una manifestación residual e irrelevante.

El dominio de la inteligencia y el dinero determina un dominio falto de carácter, pues «las personas y las cosas están determinadas de modo fijo, individual, sin diferencia y con exclusión de todo lo demás» ${ }^{61}$. La inteligencia se configura como «un espejo indiferente de la realidad». Esa falta de carácter de la inteligencia se muestra en la ausencia de "la unilateralidad selectiva que constituye el carácter». La inteligencia deriva hacia la operación y el procedimiento. En último término, sólo lo que es susceptible de ser subsumido bajo el procedimiento es relevante para la inteligencia. Los procesos sociales objetivados se expresan como despliegue de procesos sociales subsumibles bajo reglas de carácter. La falta de carácter de la inteligencia y el dinero subyace en la transformación de la política en simple administración y conciliación entre intereses. La paz y el consenso como fines resulta ser «la consecuencia positiva de aquel rasgo negativo de la falta de carácter» ${ }^{62}$. La sociedad se organiza a partir de la homogeneidad del dinero, que se transforma en «el punto central en torno al cual oscila la actividad de aquellas profesiones con libertad ilimitada» ${ }^{63}$.

La autonomía del yo y su voluntad había llevado a Nietzsche a la formulación de un nuevo principio moral, basado en el reconocimiento de la fuerza. La nueva evaluación tenía en su centro al superhombre, al hombre situado fuera del mundo empírico, y que sustituiría al último hombre. En su lugar, Simmel muestra un mundo en el que el último hombre ocupa el lugar central. El último hombre, que Nietzsche quiso barrer en el principio de la nueva evaluación moral, no ha desaparecido, sino que se instala como un ser disociado entre personalidad y función. Este hombre habita en un mundo en el que todos los fines y jerarquías aparecen bajo una determinación exclusivamente técnica, en el que la violencia se ha sublimado en las relaciones monetarias. El poder no se hace visible como confrontación de voluntades, como enunciaba la nueva evaluación, sino como el pacífico discurrir de la lógica del intercambio regida por el dinero. Es el habitante del mundo del dinero, regido por la inteligencia sin carácter $^{64}$. A ese hombre el mundo se le aparece como lo dado, como una realidad irreformable ente la que sólo cabe o bien adaptarse o retirarse en un místico camino individual de salvación. En este mundo, el principio de Bentham de la máxima felicidad para el mayor número posible se constituye en la única utopía.

La configuración del mundo de la autonomía individual y la objetividad del orden de las funciones regido por el dinero, compone el aspecto trágico de la descripción de la modernidad. Lo trágico es lo que sumerge al pensa-

61 Simmel (1977: 540).

62 Ibid.: 542.

${ }^{63}$ Ibid.: 542.

${ }^{64}$ A ese mismo hombre se referirá Weber, describiéndolo como carente de convicciones y para quien tanto los criterios de funcionalidad como de éxito determinan su actuación. 
miento en un complejo de conclusiones contradictorias, de opuesta significación. Lo trágico arroja una permanente tensión que pone a prueba al pensamiento y lo expulsa del paraíso de las certezas. Weber aludirá al mismo aspecto cuando describe la doble cara del capitalismo, como una fuerza material de progreso y a la vez de servidumbre del ser humano en unas estructuras burocráticas ${ }^{65}$.

En Simmel está presente esta tensión. El dinero supone la autonomía del ser humano, la realización independiente del deseo. Esto supone la separación respecto de los demás, el cierre autista sobre uno mismo y la relación exclusiva con los objetos. La libertad individual es la antítesis de la sujeción personal, del dominio por la voluntad del otro. En la premodernidad la conciencia colectiva no dejaba espacio a la conciencia individual. Esto es superado por la libertad en el mundo regido por el dinero. Su contrapunto es el aislamiento, la libertad como algo negativo, como distancia, que confina al ser humano a ser el habitante de un mundo desértico en donde, desaparecidos los otros, todo es calculable y seguro.

\section{BIBLIOGRAFÍA}

Cusa, N. de (1991): The Catholic Concordance (Cambridge).

GonzÁlez LEÓN, R. (1996): «Dinero y acción racional según L. von Mises», en Política y Sociedad, núm. 21 (Madrid).

Heidegger, M. (1991): Nietzsche, vol. I (San Francisco).

- (1993): Basic Writtings (Londres).

Hutcheson, F. (1969): A System of Moral Philosophy (Hildesheim).

Leslie, C. (1876): "On the Philosophical Method of Political Economy», en Hermathema, num. 4 (Dublín).

Mises, L. (1985): L'action humaine (París).

Muralt, A. (1978): La structure de la Philosophie Politique Moderne. D’Occam à Rousseau, "Cahiers de la Revue de Théologie et de Philosophie» (Geneve).

- (1985): La métaphysique du phénoméne (París).

Nietzsche, F. (1968): The Will to Power (New York).

Simmel, G. (1977): Filosofia del dinero (Madrid).

- (s.f.): Schopenhauer y Nietzsche (Madrid).

- (1986): El individuo y la libertad (Madrid).

${ }^{65}$ Es lo opuesto a las descripciones que desembocan en un horizonte homogéneo. El final optimista de un mundo feliz o el final pesimista de un mundo desgraciado, permiten la confortable instalación en una perspectiva unilateral, plena de certezas y seguridades psicológicas. 


\begin{abstract}
The notion of modern freedom is narw related with individual freedom. The Simmel' thesis is grounded in the principle that no human being established social relations, is teh money tha establisched social relations. Individual freedom suppousse that indivudual is closed around himself. Bymeans of money individuals have the capacity to calculate and prevent the fulfilment of the desires.
\end{abstract}

